\title{
Identity Management in an Institution of Higher Education: A Case Study Using Structural Coupling and Fractal Enterprise Model
}

\author{
Ilia Bider $^{1,2 *}$ and Erik Perjons ${ }^{1}$ \\ ${ }^{1}$ DSV - Stockholm University, Stockholm, Sweden \\ ${ }^{2}$ ICS - University of Tartu, Tartu, Estonia \\ \{ilia, perjons\}@dsv.su.se
}

\begin{abstract}
There are several ways of defining organizational identity and identity management. This article considers a less exploited one, namely, defining identity as a set of structural couplings that the organization has, and identity management as an activity aimed at maintaining these couplings. The concept of structural coupling comes from biological cybernetics, and it means that a system during its evolution becomes entangled with few other systems. The system at hand evolves together with these systems, adapts to them and causes them to adapt to it. The concept of structural coupling is applied in a study of an institution of higher education. To identify structural couplings, the authors use a so-called Fractal Enterprise Model that presents both internal structure of an organization and its business environment. The article analyzes to which elements of the environment an institution of higher education is structurally coupled and how the identity maintenance is arranged. The article provides examples of how well maintaining identity works in practice based on reflections on the authors' experience of working in the department. The article concludes with suggesting a generic procedure for identifying structural couplings and defining a strategy of maintaining these couplings.

Keywords: Organizational Identity, Fractal Enterprise Model, FEM, Viable System Model, VSM, Structural Coupling.
\end{abstract}

\section{Introduction}

Maintaining organizational identity belongs to the vital functions of an enterprise/organization. In Viable Systems Model (VSM) [1], this function is entrusted to the highest-level management system called System 5. Dependent on the author, System 5 is called Identity management function, as in [2], or Policy management function, as in [3] (meaning that policies are aimed at identity management). Identity is also present implicitly or explicitly in all levels of strategy work,

\footnotetext{
*Corresponding author

(C) 2021 Ilia Bider and Erik Perjons. This is an open access article licensed under the Creative Commons Attribution License (http://creativecommons.org/licenses/by/4.0).

Reference: I. Bider, E. Perjons, "Identity Management in an Institution of Higher Education: A Case Study Using Structural Coupling and Fractal Enterprise Model,” Complex Systems Informatics and Modeling Quarterly, CSIMQ, no. 27, pp. 60-86, 2021. Available: https://doi.org/10.7250/csimq.2021-27.03

Additional information. Author ORCID iD: I. Bider - https://orcid.org/0000-0002-3490-6092, and E. Perjons https://orcid.org/0000-0001-9044-5836. PII S225599222100156X. Received: 8 June 2021. Accepted: 19 July 2021. Available online: 30 July 2021.
} 
as defined in [4]:

1. Doctrine or policy, which defines who we are.

2. Infrastructure/capability, which defines what infrastructure/technology we should use in our business, and what capabilities we need to develop.

3. Grand strategy, which defines in which sector to operate and with whom to make alliances.

4. Strategy, which defines our structural couplings with the external world, e.g., competitors, collaborators, markets. The questions to answer here are whether we are a heard leader, part of a heard, an independent, etc.

Though maintaining identity is a function of the organization itself, the identity as such, is what an observer, external or internal, sees, not what the organization defines on its own, which creates a paradox [2]. Also, the identity exists independently of whether or not it is explicitly known to and maintained by the organization. Managing identity without really knowing what it is may be disastrous for the organization [5], thus understanding its own identity, i.e., how the organization is seen by the others, should precede any active actions related to identity management. This understanding is also needed for planning any radical change aimed at changing the organizational identity, as such change needs to be visible outside.

The literature on organizational identity in the field of Management is vast, starting with a seminal work [6] from 1985, revisited in [7] by one of its authors in 2006. The works on identity from the Management field are providing many insights about the organizational identity. However, in this article, we are interested to look at the identity from a system theoretical perspective, to see whether such perspective can give interesting insights in the area of identity management. Reviewing articles on identity from the systems theory perspective, especially related to VSM and its System 5, we have chosen to test an approach suggested in [5]. This approach is based on the idea that maintaining identity is equal to maintaining structural couplings to the key elements of the environment in which the organization operates. The idea, in its own turn, is inspired by works from biological cybernetics [8].

While [5] defines the idea of using the concept of structural coupling to understand identity and identity management, it does not present a systematic procedure of how to find all structural couplings and how to use the findings in identity management decisions. In this article, we try to narrow this gap by suggesting a new approach for (1) identifying and (2) managing identity. The approach is based on employing an enterprise model of organization for both identifying structural couplings, and planning changes to maintain them. Naturally, such a model should be able to represent both structural couplings, and parts of the organization that can be changed in order to maintain these structural couplings. To test the approach in practice, we use a case study related to identity management in the organization to which the authors belong. As the approach is under development, at this stage, we cannot apply it directly in the decision making inside the organization. Instead, we use the approach to explain decisions made in the past period of around 20 years. The thinking behind applying the approach for explaining past decisions is as follows: If we can clearly explain these past decisions using the approach, it gives some basis to believe that the approach can be used for making new decisions.

The organization in the focus of our case study is an institution of the higher education, more exactly, a department of a university. Among the previous works related to organizational identity, there are many that are devoted to identity of a university; for instance, a literature review [9] considers 120 peer reviewed publications in this area. However, as with general literature related to identity concept, none of them suggests a system theoretical model that can be used for understanding and managing identity of the institution of higher education, such as a department, school, or faculty.

This article continues the investigation of organizational identity started in our previous paper [10], which uses the same business case. In it, we have built a simplified model that reveals structural couplings of an organization. This model takes into consideration two main types of structural couplings, i.e., couplings to: (1) who produces input that is used in the organization, and 
(2) who consumes output produced by the organization. In addition, it uses Viable System Model (VSM) [3] to determine structural couplings to the upper management and regulators. It also adds a coupling to the geographical location. Using our earlier simplified model of structural couplings, we could explain, at least some of the past decision related to identity management. However, our earlier model lacked a consistent theoretical base, which prevented its further development.

In this article, we return to the topic of organizational identity using a so-called Fractal Enterprise Model (FEM) [11] instead of a simplified model developed in [10]. Though FEM already existed at the time we worked on [10], it did not have enough concepts to cover structural couplings. In the latest works [12], [13], FEM has been extended with new concepts that allows to use it for identifying structural couplings. In this article, we use the same business case and the same decisions that were analyzed in [10], but we do it in a different way. Due to having the same topic, business case and examples, the current article can be considered as an extension of [10]. At the same time, it can be considered as continuation of [13], as it adds additional rules to how identify structural couplings based on FEM.

The rest of the article is structured in the following way. In Section 2, we give an overview of the research approach. In Section 3, we present the knowledge base that underlines our work. In Section 4, we discuss a FEM-based model of the educational institution and identify elements of its environment to which it is coupled. In Section 5, we present analysis of decisions made and implemented by the educational institution in order to manage its identity. In Section 6, we generalize the example suggesting a generic procedure for identifying and managing structural couplings of an organization. Finally, in Section 7, we summarize the results of our work and draw plans for the future.

\section{The Research Approach}

The research presented in this article belongs to the Design Science (DS) paradigm [14], [15], which focuses on looking for generic solutions for problems, known, as well as unknown. The result of a DS research project can be a solution of a problem in terminology of [15], or an artifact in terminology of [14]; alternatively, the result can be in the form of "negative knowledge" stating that a certain approach is not appropriate for solving certain kind of problems [15].

This work simultaneously belongs to two DS projects. The first project, started with paper [10], aims at developing a model-based methodology for understanding and managing organizational identity. The current work can be considered as a second cycle in the project. This cycle, according to the classification from [16], concerns Improvement of the solution/artefact developed in the previous cycle. The second project is related to finding new applications areas for FEM. This project has already had a number of cycles of the Problem seeking type in the classification from [16], where FEM was tested for solving various problems. In respect to the FEM project, the current article continues the works started by [12] and [13], which have extended FEM in a way that it becomes possible to use it in combination with the concept of structural coupling.

The approach to identity management being developed in this work is based on the following assumptions:

- Following [5], identity is treated as a set of structural couplings of an organization, and identity management as an activity aimed at maintaining organization's structural couplings.

- Structural couplings of an organization can be identified through analysis of FEM for this organization. In this article, we do it by following the rules suggested in [13], extending their set when it shows to be insufficient for our example.

- The model, in which structural couplings are identified, can be used in decision-making related to identity management.

As we are in an early phase of the solution/artefact development, we cannot suggest the decision makers to use our approach directly. Instead, we use it to explain identity-related decisions made in the past. For this end, we analyze the history of decision-making of the institution of higher 
education for which we have worked for two decades. The choice of this business case is made based on our intrinsic knowledge of the history. We will discuss both positive decisions, as well as negative ones. Holding no high-ranking position in the department diminishes any incitement for us to hide the decisions that proved to be unsuccessful. We try to analyze all decision objectively, minimizing any possible bias. Being able to explain past decisions based on the approach gives an indication that this approach can be used for making decisions as well.

\section{Knowledge Base}

Knowledge base is one of the terms related to DS research. It refers to the cumulative knowledge that is used in developing a new solution/artefact [17]. In this section, we review concepts, ideas and literature that is used in the development of our approach for understanding and managing identity of an organization. We also give an overview of a business case that we have used for developing and testing the approach.

\subsection{Business Case}

Our study is being completed at the Department of Computer and System Sciences, abbreviated to DSV, at Stockholm University. The department is engaged in research and undergraduate and graduate teaching of about 5000 students simultaneously. It runs bachelor, master, and doctoral programs in the fields of Computer Science and Information Systems. It has about 180 staff members including teachers and administrative staff. The department belongs to the Faculty of Social Sciences, which is unusual for departments of the DSV type in other universities. Usually, such departments belong to the engineering, natural science, or business schools. Both authors of this paper belong to the DSV academic staff.

In this article, we consider only teaching activity of DSV, leaving the research activity outside the scope of our study. More specifically, we concentrate on bachelor and master programs of the department, leaving $\mathrm{PhD}$ programs, which are relatively small, outside.

In Sweden, university education is free of charge for citizen and residents of EU, which constitute the majority of our students. Other students need to pay some fee, but the fee is small when comparing with other countries. Formally, Stockholm University is a governmental institution.

\subsection{Structural Coupling}

The concept of structural coupling comes from biological cybernetics, more specifically, from the works of Maturana and Varela, see, for instance, [8]. The idea of structural coupling is relatively simple; it suggests that a complex system adjusts its structure to the structure of the environment in which it operates. The adjustment comes from the constant interaction between the system and its environment. Moreover, during the system evolution in the given environment, some elements of the environment and interaction with them become more important than others. The latter leads to the system choosing to adjust to a limited number of environmental elements with which it becomes structurally coupled. According to Luhmann [18], a system deliberately chooses to limit its couplings to few elements, as a strategy of dealing with the complexity.

An element of the environment to which a system becomes coupled, being a system on its own, may, in turn, adjust its structures to the given system, which creates interdependency between the two structurally coupled systems. The process of emergence of the structural coupling during the co-evolution of two interacting systems is represented in Figure 1. As the result of mutual interdependency, the structurally coupled systems change together, one changing itself as a reaction on changes in the other. The coupling might not be symmetrical, i.e., one system may dominate the other, making it more likely that the latter would change as a reaction on changes in the former. 


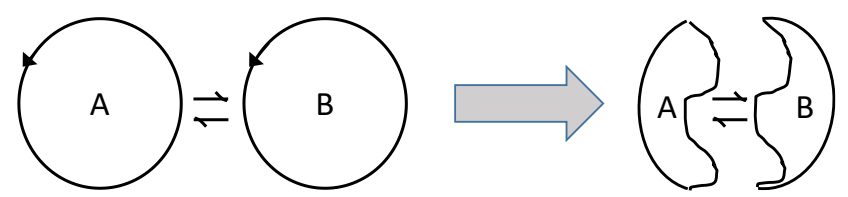

Figure 1. Emergence of structural coupling. Adapted from [19]

The concept of structural coupling along with other concepts developed by Maturana and Varela, such as autopoiesis, was adopted by other fields that use system theoretical concepts. A typical example is Social Science, to which this term was brought by Luhmann; see, for instance, [18]. However, in the domain of organizational systems, which are socio-technical systems, the usage of the concept of structural coupling is not widely spread.

\subsection{Viable System Model (VSM)}

As this work is, at least partially, based on VSM, we give a short overview of this model. VSM has been developed by Stafford Beer [1] and his colleagues and followers, see for instance [3], [20]. VSM represents an organization as a system functioning in its environment. Furthermore, VSM differentiates two parts in this system: Operation and Management. In its own turn, Operation is split into a number of semiautonomous operational units, denoted as System 1, that have some mechanism to ensure their coordination. This mechanism, denoted as System 2, is called Coordination. Management, in turn, is split in three parts, denoted as System 3, System 4, and System 5, which is presented in Figure 2. Dependent on the author, these systems may be dubbed differently, see Table 1, but they have more or less the same meaning, see the last column in Table 1.

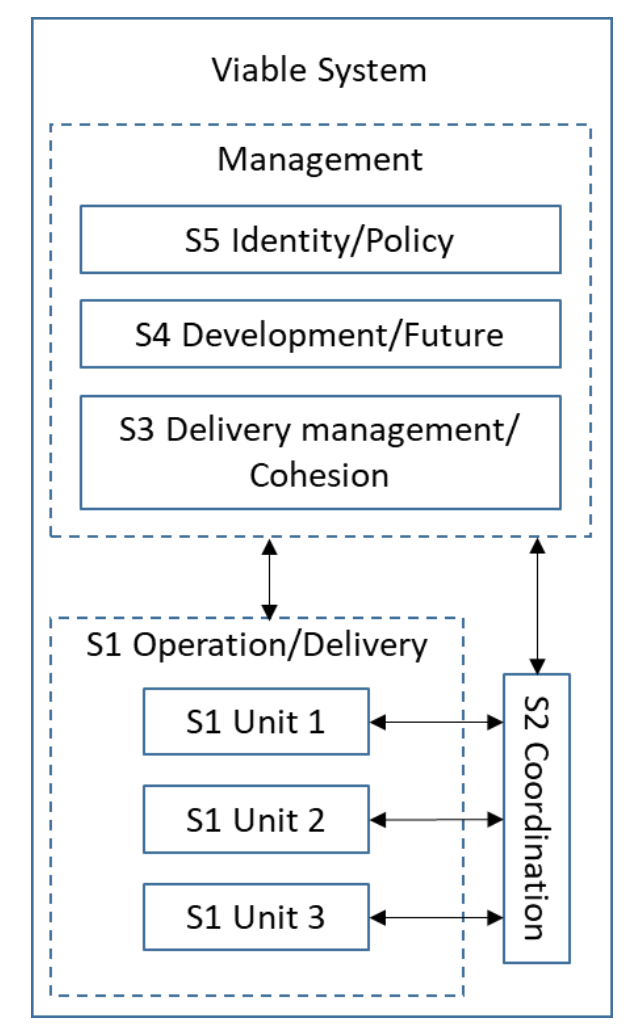

Figure 2. A simplified diagram of VSM model

Note that components listed in Table 1 seldom coincide with the organizational structure of a particular organization. Different components can be manned by the same people. This, for instance, happens in a small enterprise where the same group of people does the job on several or 
on all levels. The components in this case are differentiated not by who is doing the job, but by the nature of activities performed, e.g., policy document writing belongs to System 5, while completing a customer order belongs to System 1.

Table 1. Components of VSM

\begin{tabular}{|l|l|l|}
\hline $\begin{array}{l}\text { Identifi- } \\
\text { cation }\end{array}$ & Naming & Function \\
\hline System 1 & $\begin{array}{l}\text { Operations, } \\
\text { Implementation, } \\
\text { Delivery }\end{array}$ & $\begin{array}{l}\text { Producing and delivering products and services for external customers, thus } \\
\text { actively interacting with the environment }\end{array}$ \\
\hline System 2 & Coordination & Coordinate work of operational units included in System 1. \\
\hline System 3 & $\begin{array}{l}\text { Control, } \\
\text { Delivery } \\
\text { management [2], } \\
\text { Cohesion [3], } \\
\text { Homeostasis [21] }\end{array}$ & $\begin{array}{l}\text { Managing operational units (System 1), and establishing/maintaining } \\
\text { coordination mechanism (System 2). Making the semiautonomous units } \\
\text { function well as a whole (cohesion) in the current business environment } \\
\text { (homeostasis). }\end{array}$ \\
\hline System 4 & $\begin{array}{l}\text { Intelligence [3], } \\
\text { Future, } \\
\text { Deterostasis [21] } \\
\text { [20] }\end{array}$ & $\begin{array}{l}\text { Forward looking adaptation to possible future changes in the environment } \\
\text { through identifying trends and preparing to changes or affecting the } \\
\text { environment in the desired direction (intelligence). System 4 allows changing } \\
\text { from one homeostasis (now) to possible homeostasis in the future thus } \\
\text { allowing the system to function in a heterostatic environment. System 4 is } \\
\text { considered as including development, marketing and research. }\end{array}$ \\
\hline System 5 & $\begin{array}{l}\text { Identity [21] } \\
\text { (management), } \\
\text { Policy [3], [20] } \\
\text { (management) }\end{array}$ & $\begin{array}{l}\text { Solving conflicts between System 4 and System 3 [2]. Permitting System } 4 \\
\text { to introduce changes despite the conservatism of System 3, and not allowing } \\
\text { System 4 to change the identity of the whole system that exists via } \\
\text { functioning of Systems 3,2, 1. This is done through designing, maintaining } \\
\text { and imposing policies that stay in place even when changes designed by } \\
\text { System 4 are implemented in Systems 3, 2, 1. }\end{array}$ \\
\hline
\end{tabular}

VSM has a recursive nature, meaning that any unit of System 1 can be considered as a viable system on its own; thus, it can be represented with the help of VSM, as shown in Figure 2. Note also, that besides the five systems presented in the table, there is a so-called System $3 *$ that consists of random inspection of System 1 by System 3 of the same, or higher level in the recursive decomposition.

\subsection{Structural Coupling and Organizational Identity}

The idea of using structural coupling for modeling and managing organizational identity was first introduced by Patrick Hoverstadt in [5]. It came as an opposition to the more accepted ways of defining identity, that is, through the concept of purpose. Paper [5] discusses two ways to define a purpose: (a) a purpose defined as what the management/designers have in mind, and (b) a purpose defined by POSWID (Purpose Of the System is What It Does), the concept introduced by Stafford Beer, an inventor of VSM. In [5], Hoverstadt argues that both definitions have conceptual drawbacks. Then, to overcome the problems of the purpose-based definitions, [5] presents an idea of defining identity as a set of structural couplings the organizational system has in its environment. The identity management is defined as maintaining (and strengthening) these structural couplings.

The definition of identity as a set of structural couplings, actually, corresponds to the commonsense sayings of the sort "Tell me who your friends are and I'll tell who you are" and "Tell me who your enemy is, and I will tell you who you are". In both saying the focus is on structural couplings to friends and enemies. In the enterprise world, friends can be substituted by customers and suppliers, and enemies - by competitors. The primary focus here is on the connection between the system and its environment, rather than on the internal structure of the socio-technical system (organization). This focus does not mean that the internal structure of the socio-technical system 
(organization), e.g., culture, methods and technology, is not relevant for its identity. This internal structure must correspond to the set of structural couplings. Firstly, the organization needs to adjust its structure to the changes in the structurally coupled systems. Secondly, it should understand how the changes initiated from within the organization can affect its structural couplings. There is always a risk that a change will break a structural coupling, which may not have been anticipated when the change was under planning. In case of a "friend", i.e., a customer or supplier, the "friendship" can be ruined, while in case of an "enemy", e.g., a competitor, a status-quo can turn into open "war of attrition". Some examples of such situations are presented in [5], others can be found elsewhere, e.g., on the Internet.

Note that defining identity management as maintaining structural couplings to the given set of elements in the organization's environment does not exclude the organization changing its set of structural couplings. Such change may be more or less radical. In a less radical change, one structural coupling is substituted by another of the same sort. In a more radical change, the nature of coupling (or the types of the coupled systems) changes, see a discussion on this topic in [12].

Note, also, that there are a number of approaches in the literature mentioned in [9] that use similar ideas to the ones used in the approach based on structural coupling. To these, for instance, belong the Stakeholders approach [22], and Institutional logic [23]. However, none of them totally coincides with the view on the identity based on the concept of structural coupling, and none of them is rooted in systems theory.

\subsection{Fractal Enterprise Model}

In this section, we give an informal overview of the Fractal Enterprise Models (FEM) introduced in our earlier works, especially in [11], and in the extended form in [13]. The basic version of FEM includes three types of elements: business processes (more exactly, business process types), assets, and relations between them, see Figure 3, in which a fragment of a model describing operational activities of DSV is presented.

Graphically, a process is represented by an oval, an asset is represented by a rectangle (box), while a relation between a process and an asset is represented by an arrow. We differentiate between two types of relations in the fractal model. One type represents a relation of a process "using" an asset; in this case, the arrow points from the asset to the process and has a solid line. The other type represents a relation of a process changing the asset; in this case, the arrow points from the process to the asset and has a dashed line. These two types of relations allow tying up processes and assets in a directed graph.

In FEM, a label inside an oval names the given process, and a label inside a rectangle names the given asset. Arrows are also labeled to show the type of relations between the processes and assets. A label on an arrow pointing from an asset to a process identifies the role the given asset plays in the process, for instance, workforce, or infrastructure. A label on an arrow pointing from a process to an asset identifies the way in which the process affects (i.e., changes) the asset. In FEM, an asset is considered as a pool of entities capable of playing a given role in a given process. Labels leading into assets from processes reflect the way the pool is affected, for instance, label Acquire identifies that the process can/should increase the pool size.

Note that the same asset can be used in multiple processes playing the same or different roles in them, which is reflected by labels on the corresponding arrows. It is also possible that the same asset plays multiple roles in the same process. In this case, several labels can be placed on the arrow between the asset and the process. Similarly, a process could affect multiple assets, each in the same or in different ways, which is represented by the corresponding labels on the arrows. Moreover, it is possible that a single process affects a single asset in multiple ways, which is represented by having two or more labels on the corresponding arrow. 


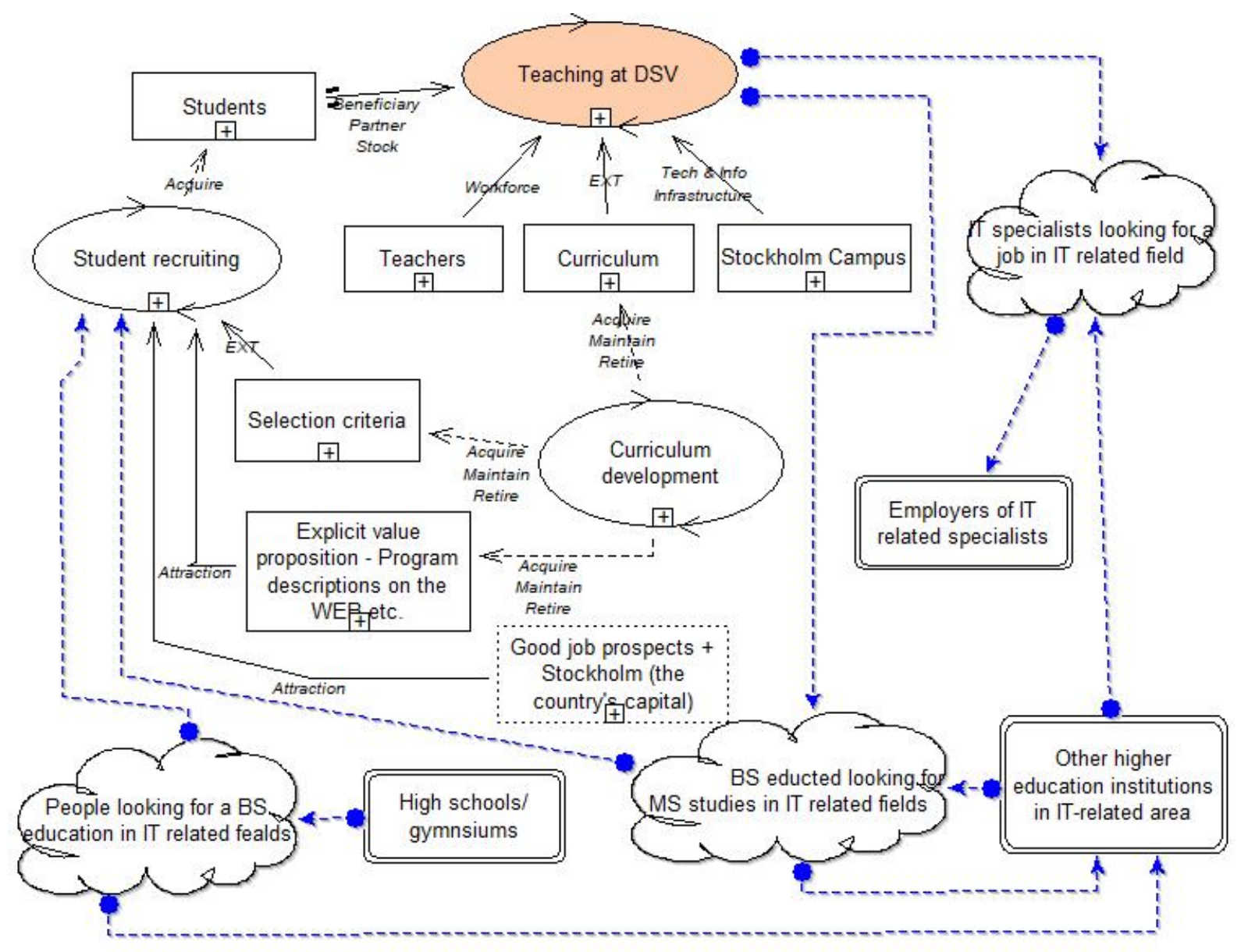

Figure 3. A fragment of FEM for DSV

Labels inside ovals (which represent processes) and rectangles (which represent assets) are not standardized. They can be set according to the terminology accepted in the given domain, or be specific for a given organization. Labels on arrows (which represent the relations between processes and assets) are standardized. This is done by using a relatively limited set of abstract relations, such as, Workforce or Acquire, which are clarified by the domain- and context-specific labels inside ovals and rectangles. Standardization improves the understandability of the models.

The relations that show how an asset is used in a process are as listed below (more full explanation see in [11]):

1. Beneficiary - an agent, a person or organization, e.g., a customer, who gets value from the process for which the agent or somebody else is going to pay. Beneficiary relation can be used for a so-called primary process, which belongs to System 1 in VSM terminology.

2. Workforce - people trained and qualified for employment in the process, e.g., workers at the conveyor belt; physicians; researchers.

3. EXT-a process execution template, e.g., a software development methodology accepted in a software vendor company. EXT does not need to be in the form of a procedure or algorithm. For instance, a policy document on equal opportunities in recruitment of staff is regarded as an EXT for the recruitment process.

4. Partner - an agent, a person or organization, not employed by the given organization, who participates in the process.

5. Stock - a stock of things, e.g., parts or manufacturing orders that are used in the process. The main characteristic of stock is that each process instance depletes this asset by consuming one or more elements from it. Thus, the stock needs to be constantly refilled by some process. 
6. Technical and Informational Infrastructure - an equipment required for executing the process. This, for instance, can be: a production line, computer, communication line, building, software system, database.

7. Organizational Infrastructure - a unit of organization that participates in the process. This, for instance, can be: a sales department, or software development team.

8. Means of Payment - any kind of monetary fund that is needed to pay participating stakeholders, e.g., suppliers if such payment is considered as part of the process. We will not use this particular asset role in this article.

9. Attraction - something that helps to "acquire" stakeholder (beneficiary, workforce, partner), e.g., a salary, reputation, value proposition, etc.

There are only three types of relations that describe how an asset is managed by a process:

1. Acquire - a process that results in the enterprise acquiring new assets of a given type.

2. Maintain - a process that helps to keep existing assets in the right shape to be employable in the business process instance of a given type.

3. Retire - a process that phases out assets that no longer can be used in the intended process.

Two new concepts were introduced to FEM in order to represent the business context of the organization and connect it to specific processes [13]. These are as follows:

- External pool, which is represented by a cloud shape, see Figure 3. An external pool is a set of things or agents of a certain type. As an example, in Figure 3, there are three such pools. The label inside the external pool describes its content.

- External actor, which is represented by a rectangle with rounded corners. An external actor is an agent, like a company or person, acting outside the boundary of the organization. The label inside the external actor describes its nature. If a model element represents a set of external actors the box has a double line, see Figure 3 which has three external actors of this kind.

External pools and external actors may be related to each other and to other elements of the FEM diagram. Such a relation is shown by a dashed arrow that has a round dot start. More exactly:

- A business process may be connected to an external pool with an arrow directed from the pool to the process. In this case, the process needs to be an acquire process to one or more assets. The arrow shows that the process uses the external pool to create new elements in the asset for which this process serves as an acquire process, see examples of such relations in Figure 3 (two dashed arrows towards the process "Student recruiting").

- An external actor may be connected to an external pool with an arrow directed from the pool to the external actor. In this case, the arrow shows that the external actor draws elements from the pool. This type of relations is used to denote competitors, see, for instance, external actor Other higher education institutions in IT related area in Figure 3.

- A business process may be connected to an external pool with an arrow directed from the process to the pool. In this case, the arrow shows that the process provides entities to the external pool, see examples in Figure 3 (two dashed arrows from the process "Teaching at DSV").

- An external actor may be connected to an external pool with an arrow directed from the actor to the pool. In this case, the arrow shows that one of the actor's processes provides entities to the external pool, see examples in Figure 3 (see the dashed arrow from actor High schools/gymnasiums).

- Two pools can be connected to each other, which means that elements from one pool can move to another based on external condition (there are no examples of such relations in Figure 3, but we will discuss it later).

External pools and actors represent the environment in which an organization operates. External pools can be roughly associated with markets, e.g., a labor market, etc. External actors represent other organizations that are connected to the external pools. Dependent on the nature of the 
external pool, an external actor connected to it can be a competitor, provider, or collaborator. Note that an external organization can be an asset, e.g., partner or customer, or an external actor. The difference reveals itself in how the external organization is connected to the internal processes of the given organization (i.e., the organization in focus of modeling). An external actor is always connected via an external pool. If needed, an arrow that connects an external pool to some other element can be supplied with a label to clarify the condition on when or why the elements can be added to or withdrawn from the pool.

To make the work of building a fractal model more systematic, FEM uses archetypes (or patterns) from which a particular model can be built. An archetype is a template defined as a fragment of a model where labels inside ovals (processes) and rectangles (assets) are omitted, but arrows are labelled. Instantiating an archetype means putting the fragment inside the model at hand and labelling ovals and rectangles; it is also possible to add elements absent in the archetype, or omit some elements that are present in the archetype.

FEM has two types of archetypes, a process-assets type and an asset-processes type; there is only one archetype of the latter type. A process-assets archetype represents the kinds of assets that can be used in a given category of processes. The asset-processes archetype shows the kinds of processes that are aimed at changing the assets. The whole FEM graph is built by alternative application of the two types of archetypes in a recursive manner. Actually, the term fractal in the name of our modeling technique points to the recursive nature of the model; for more detailed explanation, see [11].

\section{Structural Couplings of DSV}

In this section, we will develop a FEM for our business case that will allow us to identify to which elements of the external environment our department, DSV, is structurally coupled. We start with Figure 3 that shows some structural couplings, and then extend the model to reveal more structural couplings. For discovering structural couplings, we will use the semi-formal rules from [13], extending the set when necessary.

We start with analyzing Figure 3 that represent several main components of DSV's business activities. It has Teaching at DSV as a main process, and Students as its main beneficiary who gets value for which somebody is willing to pay. In most cases, it is paid by the Swedish state. It also has three important assets, Teachers, Curriculum, and Stockholm Campus. Students are acquired by the Student recruiting process, which draws potential students from two external pools, one is people with high school (American term) or Gymnasium (Swedish term) degree, and the other is people with a BS degree who want to get a MS degree. These pools are connected to external actors that add to the pools (providers) or draw from the same pools (competitors). Note that the same actor may be both a provider and a competitor, as shown in Figure 3, see external actor Other higher education institutions in IT-related area.

The teaching process produces graduates that fill two external pools: (1) specialists looking for a job, and (2) bachelor graduates who want to get a MS degree. These pools are connected to external actors that add to or draw from these pools.

Asset Curriculum is managed by the Curriculum development process. Besides managing curriculum, the process manages two other assets that are used in Student recruiting, namely: Selection criteria that to some extent control recruiting (hence EXT - executable template), and Explicit value proposition for students in the form of program descriptions in brochures and on the Internet. The latter serves as an Attraction for students. Beside the explicit attraction, we put in the model a "tacit" attraction, which is shown by the dotted border of this asset. This attraction may or may not be included in the explicit value proposition, but it exists in the minds of the potential students, e.g., prospects of good job and life in a capital city. 


\subsection{Structural Coupling Related to Inbound Pools}

We will use the rule defined in [13] to identify structural couplings related to the inbound pools. The rule is defined in the following manner:

If in a FEM of an organization:

1. there is an essential process, which is not easy to remove, and

2. this process has an essential asset with high rate of depletion, which needs to be constantly filled, and which is not possible or not easy to remove or substitute, and

3. an Acquire process for this asset is connected to an external pool from which it is getting new elements to fill the asset,

then the organization is structurally coupled to the pool.

The teaching process is a primary process, which is essential for DSV, and it needs to constantly draw potential students from two external pools; this should be done each year as the existing students at DSV finish their education and cease to be part of the Student asset. Therefore, the external pools from which the new students are drawn satisfy the above rule. Thus, DSV is structurally coupled to two inbound pools as it depends on the size and the quality of elements in them.

In addition to the above rule, [13] presents a rule of indirect structural coupling that is defined in the following manner:

If an organization is structurally coupled to an external pool, it may also be structurally coupled to the actors that fill this pool, or draw from the pool (e.g., competitors).

According to this rule, DSV might be structurally coupled to high school/gymnasium and to other institutions of higher education. Whether this is the case, depends on the size of the pool and the strength of the competition. According to the quoted statement of Luhmann [18], the system deliberately limits the number of structural couplings and uses them as information channels to the rest of the environment. Thus, connection of external inbound pools to DSV is a fact, but whether it structurally coupled to the providers and competitors is a question that needs to be answered. We will return to this question later in the article.

\subsection{Structural Couplings Related to the Outbound Pools}

Paper [13] does not give full definition of structural coupling related to the outbound pools, i.e., pools to which process of the given organization adds elements, but just mentions that it can be formulated in the same way as for inbound pools. Thus, the definition can be formulated in the following way:

If in a FEM of an organization, there is a process that constantly adds elements to an external pool then the organization could be structurally coupled to external agents that draw from this pool, and also to the external agents that add to the pool.

The logic behind this rule is simple. The outbound pool may have a limitation on its size. The limitation depends on the agents that draw from the pool, i.e., on their capacity of consuming the elements from the pool. Also, if there are other agents adding to the pool, it can create a situation of competition regarding which elements have more chances to be consumed. The rate of consumption from the pool will affect the rate at which the elements can be added, and thus will set a limit on the organization's growth.

For our DSV department, there are two outbound pools: people looking for a job, and BS graduates looking for MS studies. Through the first pool, DSV is structurally coupled to the employers of IT specialists, and, potentially, to other institutions of higher education that prepare the same kind of specialists. The potentiality may become the fact when the rate of consumption from the pool slows down and/or the IT employers start to prioritize the graduates from other institutions. 


\subsection{Structural Coupling to Geographical Location}

Paper [13] does not give any rule related to geographical location. However, the fact that DSV is located in Stockholm has a major impact on the number of students seeking enrollment in the DSV programs. Desire to live and study in Stockholm serves as an essential motivation for the candidates choosing DSV instead of its competitors in other parts of Sweden. This was confirmed by two investigations completed by our BS and MS students who interviewed the first-year students from DSV programs.

FEM does not have special means to identify geographical location. Thus, the rule needs to refer to something outside the model. The proposed rule is expressed as follows:

If the major activities in an essential process for the organization are carried out in a geographical location and cannot be moved to another location without substantial disturbance of the organization's functioning, then the organization is structurally coupled to this geographical location.

The scope of geographical location depends on the process in question. For instance, for DSV, changing the place of the campus does not disturb operations, as long as it is in the Stockholm region. This has been done before without much disturbance. For other organizations, the meaning of geographical location can be different, it can be a town, city, country, or continent. The reason why changing the location for activities of a process may disturb the business depends on what the organization does. For DSV, disturbance, in the first place, will lead to losing the attraction for the students having a big city life. It would force DSV to compete with peripheral institutions in the IT domain. In the second place, not all teachers would like to move, but it is much lesser problem, new ones could be hired.

Note that being subjected to harder competition when losing an established base can serve as a sign of structural coupling to a geographical location for other types of organization as well. The reasons can be the access to the workforce, or any other resources that are needed for proper functioning.

\subsection{Structural Coupling to Upper Management and Regulators}

In paper [10], we have suggested that in addition to structural couplings related to pools and geographical location, DSV is structurally coupled to the upper layers of management system, i.e., System 3, 4, and 5 in VSM terms. More specifically, DSV is coupled to Stockholm University and to the Swedish state. This type of structural couplings is not covered by the rules presented in [13]. For this end, we will extend the model in Figure 3 with new elements, see Figure 4. To avoid overcomplication of the model, we omit some elements from Figure 3 that are not relevant to the current discussion. In particular, we remove all elements related to the external pools, and also assets Teachers, and Stockholm campus.

In Figure 4, there are four new assets, each playing a role of EXT, i.e., assets that control the processes to which they are connected. Beside these assets, Figure 4 depicts the processes that manage them. Three of these EXT assets, in Figure 4, have light aquamarine background. This background color indicates that, though the assets are used in internal processes, they are managed by external organizations. In Figure 4, the processes that manage these assets are also marked with the light aquamarine color to show that they are not part of DSV. To further clarify the nature of the external assets and processes, we use border colors to identify to which organization these assets and processes belong to. This approach was suggested in [24] that deals with multiorganizational business processes. More specifically, the green border identifies assets and processes that belong to Stockholm University (SU), while the blue border identifies the assets and processes that belong to a Swedish governmental office, namely, the Swedish Higher Education Authority (SHEA) [25]. 


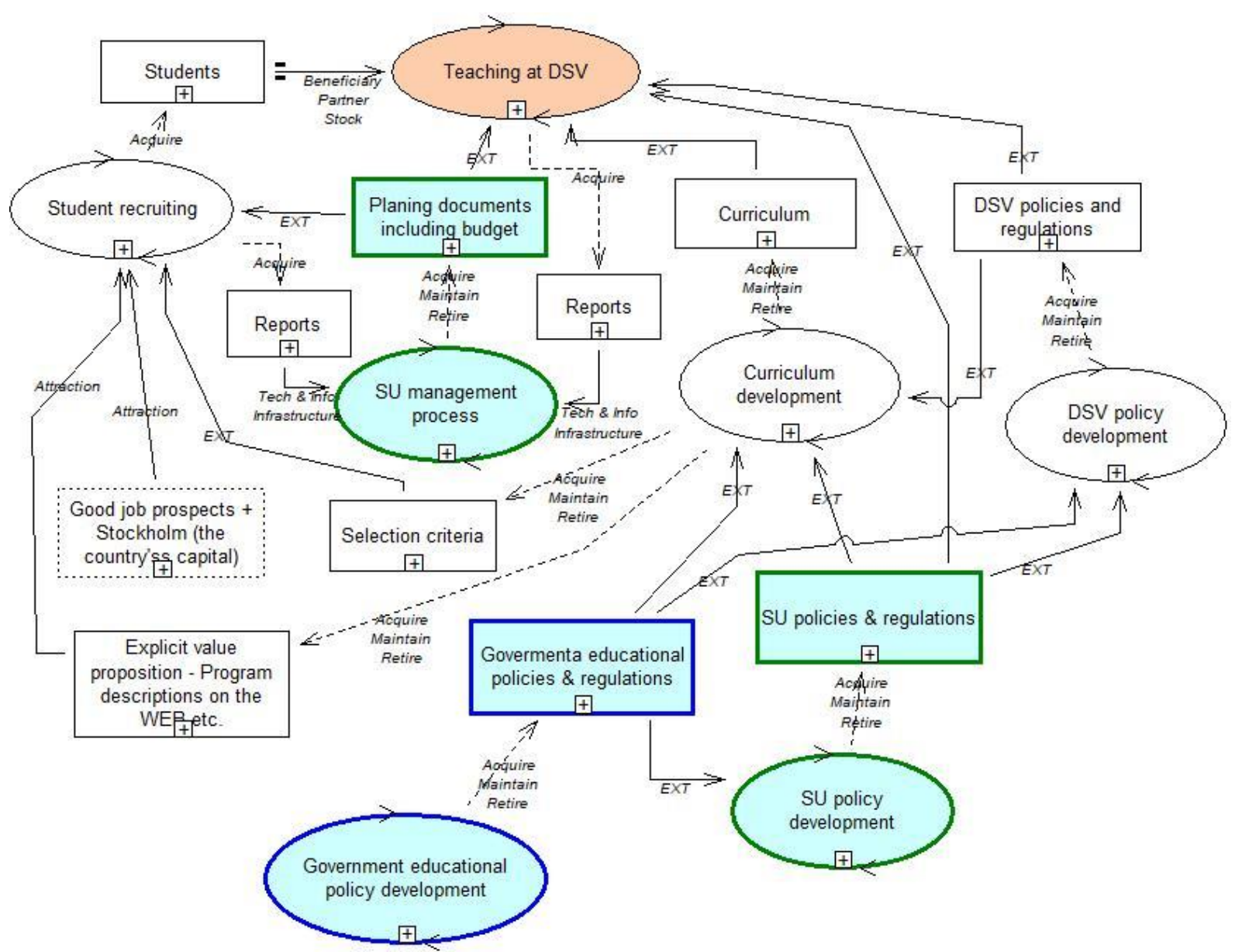

Figure 4. FEM of DSV extended with externally created assets

Having an asset of EXT type created by a third party does not automatically imply that the creator belongs to the structural couplings of the organization. An organization can choose to use such an asset because of its fitness to the process at hand, e.g., accept a project management methodology. In this case, the structural coupling might not exist. The structural coupling appears when the organization is obliged to use this EXT asset (for instance, according to governmental regulations) and need to report on the usage and/or can be subjected of a "surprise" inspection from the creator of the asset. From the VSM point of view, this happens when the creator belongs to the upper management of the given organization, directly, or somewhere in an upper layer of VSM recursive decomposition. However, a structural coupling to an external asset creator does not need to be a coupling to the management. An organization can voluntary choose to certify itself for something with a third party, and use this certification as part of its offering to the customers. Such certification may include the obligations for back reports, and allowing inspections.

In Figure 4, asset Planning documents created by SU dictates what resources are available for DSV to conduct teaching (including the number of students that can be enrolled). From the point of view of VSM, it is created by System 3 of the university. DSV has an obligation to report on the achievements related to the use of these resources, which is represented in Figure 4 by assets labeled as Reports. Other EXT assets created by external parties concern policies that affect curriculum development and conducting the teaching process. From the VSM point of view, these assets are produced by System 5 of Stockholm University and Swedish government respectively. DSV is not required to report on following these policies, but should expect that an inspection to check the situation can happened at any time. One of the examples of such inspections is discussed in this article.

Summarizing the discussion above, we can formulate a new rule on structural coupling in terms of FEM, and without references to VSM, in the following way: 
If in a FEM of an organization, there is an EXT asset that is created by a third party, and the organization needs to produce reports related to this asset back to this party, or/and can expect an inspection to check the compliance of processes related to this asset, then the organization could be structurally coupled to the third party from which the asset originated.

Whether the structural coupling takes place depends on how easy it is to comply to it, and how important this asset is for the business. For instance, if the external certification does not work sufficiently well for attracting customers, the structural coupling may not exist. As we show in an example in Section 5, governmental certification is essential, which strengthen the argument of DSV being structurally coupled to the Swedish government. The rule above corresponds to the rule in [4] that states that in a heavily regulated markets, an organization is structurally coupled to the regulators.

\subsection{Analysis of Structural Couplings of DSV}

A summary of structural coupling of DSV is presented in Figure 5. This diagram is similar to what was presented in [10]; however, the reasons why a certain element of DSV environment is considered a structural coupling are derived from the FEM diagrams in Figure 3 and Figure 4, rather than from a diverse set of rules related to input/output, VSM, and geographical location.

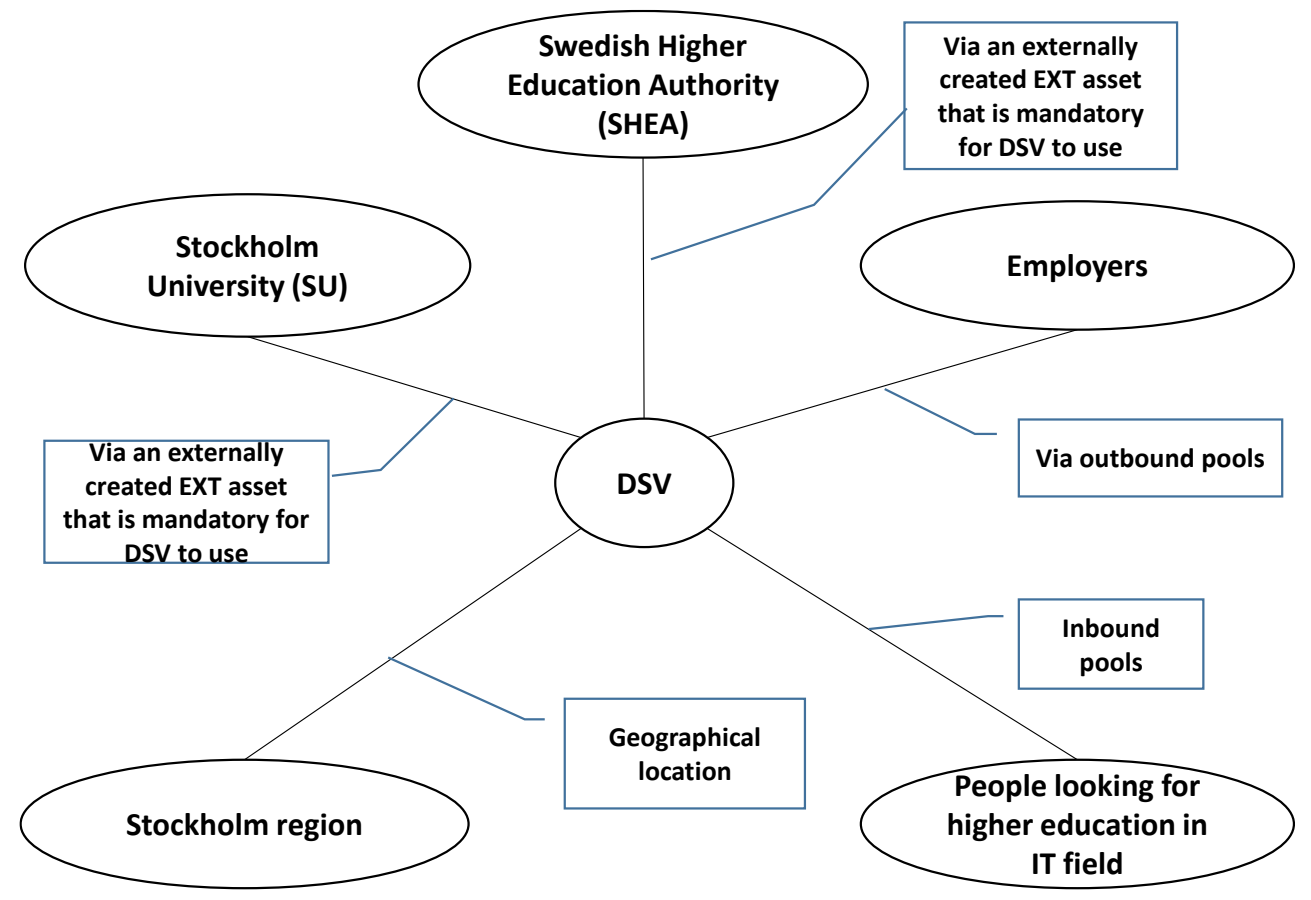

Figure 5. Structural couplings of DSV

In the subsections below, we investigate the nature of the connection between DSV and its structural couplings based on investigations completed by our MS and BS students.

\subsubsection{DSV - People looking for higher education in IT field}

Investigation shows that DSV is relatively anonymous among students graduating from the Swedish high schools/gymnasiums. The reason they choose to enroll are:

- Content of the programs is related to IT,

- Prospects of a good job,

- Campus in Stockholm, that is, life in a capital city,

- Being part of Stockholm University, 
- Less technical program than with some competitors, and lesser requirement on hard science subjects, such as mathematics.

From the above list, we can see that most of the identity DSV has for potential students is inherent identity from its other structural couplings, i.e., employers (prospect of good jobs), Stockholm, and Stockholm University. The last bullet above refers to the DSV competitors, which we have not included as a structural coupling; the reason being that DSV has its own niche, due to structural coupling to Stockholm and substantial demand for IT specialists in the labor market in general. The niche is strengthened via less technical programs, which differentiates DSV from other competitors in Stockholm. This position makes DSV not structurally coupled to the competitors, at least for now.

Regarding this structural coupling, the identity management goal consists of attracting enough prospected students to enroll to the courses who have a potential to finish them. DSV has no influence on the pool of potential students. It lacks the means and desire to affect the pools quantity or quality. What it does instead, it adjusts itself to the qualitative and quantitative changes in the pool, thus, taking a passive role in this structural coupling. Examples of such adjustments will be discussed in the next section.

\subsubsection{DSV - Employers of IT-related staff}

From a survey among DSV alumni conducted by the DSV administrative unit, most of the graduates find it easy to get a job after finishing a DSV program. Moreover, many of the students find a job before defending the thesis. Some of them return later to complete the thesis projects. Others never bother to get a formal diploma. Our master students conducted several interviews with recruiters who work on behalf of IT organizations. From these interviews, it followed that neither of the recruiters knew anything about DSV, but knew about Stockholm University, which, partly means that:

- There is no negative information about DSV.

- In the context of no positive information on DSV, decision to promote a candidate is done based on:

- DSV belonging to Stockholm University,

- the content of the educational program,

- and grades a candidate has received during the examinations.

Thus, even from the point of view of the employers, most of the identity is inherited from Stockholm University, ensuring a certain level of quality, the rest comes from the content of the educational program.

Regarding this structural coupling, the identity management goal consists of providing employable graduates, which is not very difficult considering the current deficit of qualified IT staff available for employment. DSV has no influence on what is happening inside the organizations that employ its graduates. DSV does not facilitate the students getting knowledge that can bring a radical change in IT development and/or usage of IT in the industry. It rather concentrates on the students acquiring enough contemporary IT-related knowledge and skills to fill the entry positions in the industry. The latter means taking a passive role in this structural coupling adjusting itself to what is happening in the industry. Examples of such adjustments will be discussed in the next section.

\subsubsection{DSV - Stockholm region}

As was discussed in Section 4.3, DSV is structurally coupled to Stockholm region, as this geographical location clearly distinguish it from the competitors that operate on the same inbound pools. Stockholm provides the students with a life of a big city, and students consider this as having a certain value. 
DSV has not much opportunity to affect what is happening in Stockholm, or make an internal change which will better adjust DSV to changes in the region. For instance, DSV does not have a possibility to improve the housing situation for the students. Moreover, it does not have much means to do anything against increasing level of criminal activity in Stockholm, excluding security measures in its own campus. Thus, no special identity management goal could be assigned in relation to this structural coupling. If suddenly Stockholm becomes an obstruction instead of attraction for the potential students, DSV would find itself in a completely different situation against its competitors, and will need to deal with it, not only with the situation in Stockholm. Also, DSV has no autonomy on decisions related to this structural coupling, as it is obliged to follow the decisions made by Stockholm University:

- mainly campus-based education (though some distance education is allowed), and

- Stockholm University is situated in Stockholm.

\subsubsection{DSV - Stockholm University}

Stockholm University (SU) functions as a management system for DSV in terms of VSM. In particular, SU regulates the DSV educational activity via a number of parameters, including the number of enrolled students for which DSV can get financial compensation, see Figure 4. It does not mean that DSV is fully controlled by Stockholm University. There are negotiations on resources and responsibilities between DSV and Stockholm University, typical for the relations between System 1 and System 3 of VSM. Regarding this structural coupling, identity management goal consists of producing the quantitative (e.g., the number of enrolled, and examined students) and qualitative (e.g., level of grades received by DSV's students during the examinations) results in exchange to the resources obtained from Stockholm University. This coupling is more symmetric than the previous ones, though some decisions of Stockholm University are non-negotiable. Also, Stockholm University as a management system has rights to make inspections (System 3* in terms of VSM) to see how everything functions "on-the-floor". The inspections can also include how well DSV follows policies designed by Stockholm University, see Figure 4. In terms of VSM, Stockholm University also includes System 5 which is responsible for policies development. Therefore, there is an additional goal of identity management related to Stockholm University, namely, complying with Stockholm University policies.

\subsubsection{DSV - Swedish Higher Education Authority}

Swedish Higher Education Authority (SHEA) is responsible for the quality of higher education in Sweden. Thus, it both creates rules and policies, and it can inspect how each institution complies with them. The influence of state-wide policies on teaching at DSV is presented in Figure 4. There is direct influence, and indirect influence through the policies developed by Stockholm University. Regarding this structural coupling, the identity management goal is to comply with policies and regulations coming from SHEA. An example related to this goal is discussed in the next section.

\subsection{Summary of Structural Couplings}

Table 2 summarizes relationships between DSV and each of the structurally coupled elements of its environment. Each coupling is analyzed according to five categories; each category has its column in the table. The first category shows how this coupling has been discovered in the FEM diagram, while the second gives a business term used to identify the relationship. The next three categories are related to identity management of the structural coupling, goal for management, whether the DSV behavior in this relationship is passive, active or neutral, and what types of actions DSV completes as a reaction on changes, or when it tries to influence changes itself. 
Table 2. Summary of Structural couplings of DSV

\begin{tabular}{|c|c|c|c|c|c|}
\hline $\begin{array}{l}\text { Structural } \\
\text { coupling }\end{array}$ & $\begin{array}{l}\text { 1. FEM } \\
\text { diagnose }\end{array}$ & $\begin{array}{l}\text { 2. Business } \\
\text { term }\end{array}$ & $\begin{array}{l}\text { 3. Identity } \\
\text { management goal }\end{array}$ & $\begin{array}{l}\text { 4. Role in } \\
\text { coupling }\end{array}$ & $\begin{array}{l}\text { 5. Reaction/ } \\
\text { influence type }\end{array}$ \\
\hline $\begin{array}{l}\text { DSV - People } \\
\text { looking for } \\
\text { higher } \\
\text { education in IT } \\
\text { field }\end{array}$ & $\begin{array}{l}\text { Inbound } \\
\text { pools }\end{array}$ & $\begin{array}{l}\text { Buyers in the } \\
\text { market of } \\
\text { higher } \\
\text { education }\end{array}$ & $\begin{array}{l}\text { Attracting enough } \\
\text { students to enroll who } \\
\text { have a potential to } \\
\text { finish }\end{array}$ & Passive & $\begin{array}{l}\text { Adjust itself to } \\
\text { changes in } \\
\text { quantity and } \\
\text { quality of the } \\
\text { pools }\end{array}$ \\
\hline $\begin{array}{l}\text { DSV - } \\
\text { Employers of } \\
\text { IT-related staff }\end{array}$ & $\begin{array}{l}\text { Outbound } \\
\text { pools }\end{array}$ & $\begin{array}{l}\text { Buyers in the } \\
\text { labor market } \\
\text { of IT } \\
\text { specialists }\end{array}$ & $\begin{array}{l}\text { Providing employable } \\
\text { graduates }\end{array}$ & Passive & $\begin{array}{l}\text { Adjust itself to } \\
\text { the changing } \\
\text { demands }\end{array}$ \\
\hline $\begin{array}{l}\text { DSV - } \\
\text { Stockholm } \\
\text { region }\end{array}$ & $\begin{array}{l}\text { Essential } \\
\text { asset } \\
\text { bounded to } \\
\text { location }\end{array}$ & $\begin{array}{l}\text { Geographical } \\
\text { region }\end{array}$ & None & Neutral & $\begin{array}{l}\text { Do nothing (until } \\
\text { there is a crises) }\end{array}$ \\
\hline $\begin{array}{l}\text { DSV - } \\
\text { Stockholm } \\
\text { University }\end{array}$ & $\begin{array}{l}\text { External } \\
\text { producer of } \\
\text { EXT assets }\end{array}$ & Management & $\begin{array}{l}\text { Producing the } \\
\text { quantitative and } \\
\text { qualitative results in } \\
\text { exchange to the } \\
\text { resources obtained. } \\
\text { Follow SU policies }\end{array}$ & $\begin{array}{l}\text { Symmetrical, } \\
\text { but more } \\
\text { passive than } \\
\text { active }\end{array}$ & $\begin{array}{l}\text { Negotiate, adjust } \\
\text { itself }\end{array}$ \\
\hline $\begin{array}{l}\text { DSV - Swedish } \\
\text { Higher } \\
\text { Education } \\
\text { Authority }\end{array}$ & $\begin{array}{l}\text { External } \\
\text { producer of } \\
\text { EXT assets }\end{array}$ & Regulator & $\begin{array}{l}\text { Comply to policies } \\
\text { defined by the state }\end{array}$ & Passive & $\begin{array}{l}\text { Adjust itself to } \\
\text { the policy } \\
\text { demands }\end{array}$ \\
\hline
\end{tabular}

\section{Using the Identity Model for Analyzing Past Decisions}

In this section, we analyze past decisions taken by DSV that are related to identity management. The cases represent identity management in relation to all structurally coupled elements of the environment. The cases are summarized in Table 3 that shows which structural couplings each case concerns (second column), and the nature of the change (third column). Note that actions listed in the third column reflect only the primary objective of the change; other parts were adjusted to this change as well.

Table 3. Summary of cases

\begin{tabular}{|l|l|l|}
\hline Case name & $\begin{array}{l}\text { Related to structural } \\
\text { coupling to }\end{array}$ & Nature of the change \\
\hline $\begin{array}{l}\text { 1. Introducing international MS } \\
\text { programs }\end{array}$ & $\begin{array}{l}\text { People looking for higher } \\
\text { education in IT field; SU }\end{array}$ & $\begin{array}{l}\text { Changing teaching language to English in } \\
\text { Master level education and developing new MS } \\
\text { programs }\end{array}$ \\
\hline $\begin{array}{l}\text { 2. Introducing a new process for } \\
\text { BS and MS thesis projects }\end{array}$ & $\begin{array}{l}\text { SHEA - Swedish Higher } \\
\text { Education Authority } \\
\text { A new process established with a set of } \\
\text { responsibilities defined for different groups of } \\
\text { academic staff. People trained to work } \\
\text { differently. New technology introduced }\end{array}$ \\
\hline $\begin{array}{l}\text { 3. Dealing with decreasing } \\
\text { levels of students' academic } \\
\text { preparedness }\end{array}$ & $\begin{array}{l}\text { People looking for higher } \\
\text { education in IT field }\end{array}$ & $\begin{array}{l}\text { Changing teaching methods and utilizing new } \\
\text { technology }\end{array}$ \\
\hline $\begin{array}{l}\text { 4. Introducing Bologna Process } \\
\text { recommendations }\end{array}$ & $\begin{array}{l}\text { SU; SHEA; Employers } \\
\text { of IT-related staff }\end{array}$ & $\begin{array}{l}\text { Reducing the number of courses, while } \\
\text { remaining relevant to Employers }\end{array}$ \\
\hline $\begin{array}{l}\text { 5. Introducing distance MS } \\
\text { programs }\end{array}$ & $\begin{array}{l}\text { People looking for higher } \\
\text { education in IT field; } \\
\text { Stockholm Region }\end{array}$ & $\begin{array}{l}\text { Changing teaching methods and using new } \\
\text { technology }\end{array}$ \\
\hline
\end{tabular}




\subsection{Introducing International MS Programs}

This story concerns structural coupling between DSV and buyers in the higher education market (People looking for higher education in IT field), and it is related to introduction of international MS programs taught in English at DSV at the end of 1990th and the beginning of 2000. Two aspects characterized the Swedish situation in this period:

- IT related boom that "sucked" many potential students to the industry. Students that started DSV programs were leaving as the industry offered them employment with quite high wages without demanding much education and skills.

- A demographic dip at the edge of 19, which is the graduation age of Swedish Gymnasium.

As the result, the enrollment of students decreased, and DSV faced the dilemma: decrease its academic staff or find another way to attract enough students to increase the enrollment. The solution taken was to attract students that were hindered to be enrolled before, namely international students in general, and from the developing countries in particular. Before that point in time, all education at DSV was carried out in Swedish. Therefore, an international student needed to spend one year for studying Swedish to be able to enroll. Also, at that time, the education was free for everyone, independently of nationality and/or place of residence.

Introducing the international MS program was not difficult, as:

- Practically all DSV courses used English reading books and articles. Therefore, there was no need to search for different reading material.

- Practically all academic staff could communicate in academic English without hindrance.

Thus, the change did not require hiring new staff, or any special training of the existing staff. The changed to English in MS courses remained at DSV from this period. However, the enrollment of international students from the developing countries, like India, China, Pakistan, while substantial in the beginning, greatly diminished at around 2012, when the Swedish government introduced fees for the students coming outside EU. By that time, however, the demographic dip has planned out, and IT boom went through the bust, which returned the students who left their education back to school.

From the point of view of FEM diagram in Figure 2, the changes concerned two assets Curriculum and Selection criteria. Changing the Selection criteria also meant that the detailed structure of the pool from which the students were drawn have changed, which is represented in Figure 6 , where the left-hand side shows the pool before the change and the right-hand side - after the change.

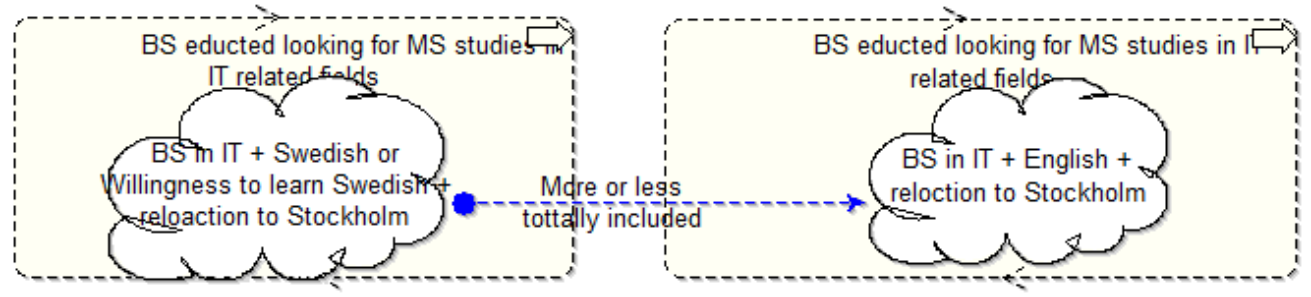

Figure 6. Changes in the structure of an inbound pool

\subsection{Introduction of a New Process for BS and MS Thesis Projects}

This story concerns structural coupling between DSV and Swedish Higher Education Authority (SHEA), or rather forgetting the importance of this coupling. In 2011, SHEA completed an inspection of DSV educational activity. The goal of the inspection was checking the quality of the education. In the past, an inspecting commission looked at the educational processes as such. This time, the commission had chosen to look only at the results of the thesis process. A number of completed thesis reports were chosen in an arbitrary manner and read by the members of the 
commission. Unfortunately, some of the master thesis they had chosen were of low quality. In short, the theses that the commission analyzed had neither proper structure, nor much of content in terms of scientific contribution.

The commission produced a report with a severe critique and demanded immediate actions threatening to close some of the DSV's master programs. The information went to mass media threatening to undermine the reputation of DSV. The DSV management tried to counter this information with the stories of high employability of the DSV graduates. The stories were true, but had no effect on the commission, as SHEA is responsible only for the quality of education (as they understand it), not for the employability of the students; the latter is the matter for DSV itself to solve.

In short, not paying enough attention to SHEA as structurally coupled element of the DSV environment led to an existential threat to DSV, comparable to the one of atom industry described in [5]. The threat required a prompt reaction; therefore, the improvement process was hastily started to increase the quality of the theses. The changes introduced via this improvement process concerned assets related to the thesis courses, including new process guidelines, new technology, staff training, and new distribution of responsibilities. The changes introduced are presented in a FEM diagram in Figure 7, where completely new assets are marked with a special background color. The changes gave results, the quality of the theses was improved, and the existential threat averted. More details on the topic see in [26].

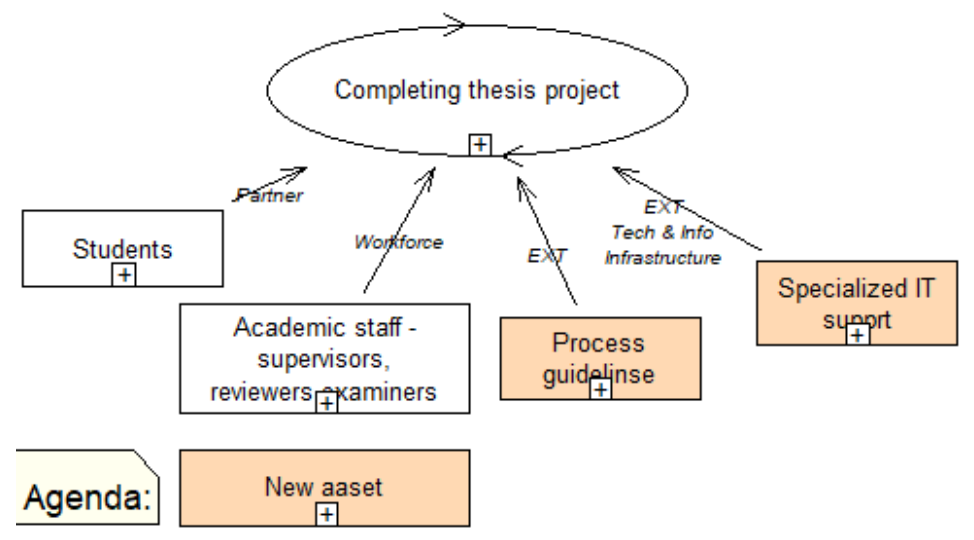

Figure 7. Changes in the thesis process

\subsection{Dealing with Decreasing Levels of Students' Academic Preparedness}

The level of academic preparedness of enrolled students in DSV programs gradually declined over the last 20 years. This is a known phenomenon observed by other universities in Sweden and other places. This phenomenon is described in details in [27]. A university needs to deal with this phenomenon in one way or another; otherwise, a great number of enrolled students will never finish their education.

Different institutions deal with this problem differently. For instance, our colleagues in Swedish Royal Institute of Technology (KTH) have chosen to introduce as so-called "basic year" where the prospective students get the knowledge that they need to study an engineering program. This allowed KTH not to introduce radical changes in the engineering programs as such. So far, DSV has not used this method of maintaining structural coupling to the buyers in the higher education market. Instead, the way of teaching has been gradually changed. Instead of relying on academic preparedness of the students, teaching started to rely on connecting the material to practical application and training.

Changes in the teaching methods, can be demonstrated on the example of course Introduction to Databases (DB) given to the first- or second-year bachelor students, for which the first author has served as a teacher during nine years. Usually, a database course is taught as an academic discipline. In our case, the topics included in the course had the following order: Conceptual 
modeling (using UML or ER) for DB design, Relational DB, Synthetic DB design (converting a conceptual model to a relational DB schema), Analytic DB design (Normalization), Relational algebra (RA), SQL, Transaction Management. Besides lectures and tutorials, the course included projects where students could really learn and understand what a database was.

The sequence above includes highly abstract topics like Normalization, and RA, near the beginning; these topics are difficult to understand for the students with less training in mathematics and abstract thinking. To improve the situation for these students, the order has been changed so that the students can have hands on experience with the relational database before going to the more abstract topics. The current sequence of topics is as follows: Conceptual modeling, Relational DB, Synthetic DB design, SQL, RA, Analytic DB design, Transaction Management, but it can also be changed, e.g., by moving Conceptual modeling and Synthetic DB design after SQL.

The above represents changes in the teaching methods, i.e., assets of type EXT. To make the change more effective, we also made changes in the technology employed by designing and introducing in teaching practice a tool called SQL Tutor [28]. The tool gives quick feedback to the students completing SQL assignments. In terms of FEM, this type of change can be represented by adding new assets of the Infrastructure type.

\subsection{Introducing Bologna Process Recommendations}

This story concerns revision of the structure of DSV education according to Bologna Process recommendations. Though the decision was taken on the governmental level, its implementation is related to the structural coupling between DSV and Stockholm University, which ultimately made the decision to implement Bologna recommendations. Before that, DSV had a two steps educational program: (1) a four-year candidate program and (2) a one-year master program. Most of the students took only the first step and went to work in the industry. According to the Bologna recommendations, the steps were redefined as: (1) a three-year bachelor program, and (2) a twoyear master program.

The situation of enrollment did not change drastically after the change. Still, most of the enrolled students finished only the first step and went to work in the industry. The actual result was that the first step became one year shorter. As the result, DSV needed to diminish the number of courses given to the undergraduate students. When deciding of what to cut, the structural coupling to Employers of IT-related staff had been taken into consideration. The subjects that were considered of high demand by Employers remained in the curriculum, e.g., knowledge of programming language Java, while other subjects, like other programming languages, disappeared from the list of mandatory courses. The latter makes the graduates less of generalists and, therefore, it may negatively affect the industry in the long run.

Note that in terms of FEM, the biggest change here concerns asset Curriculum in Figure 3 and 4.

\subsection{Introducing Distance MS Programs}

During the last years, DSV introduced and/or tried to introduce several distance programs on the MS level. The motivation was not directly related to identity management, but rather to trying to employ new technology in higher education. The main policy of SU at that time was, and still is, that the university prefers campus education.

Introduction of distance MS programs can be analyzed from the identity management perspective in two ways. Firstly, it can be seen as a way to increase a pool from which DSV draws MS students, see Figure 8. Secondly, it can be considered as an attempt to overcome limitations connected to structural coupling to Stockholm Region, though it could not be done fully due to the SU preference to run campus education. There were also some expectations that distance education might require less resources than the campus one, but these expectations have not been realized in full. 

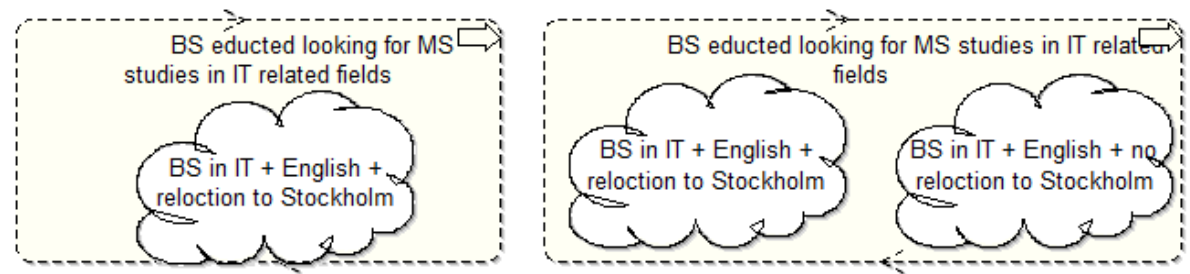

Figure 8. Extending the pool from which the students are drawn - from left to right

The possibility to introduce distance programs is connected to new technology that facilitates online education. Besides using new technology (an asset in terms of FEM), introducing distance education required changing the ways of teaching (EXT type of assets). Here, our previous work on simulated apprenticeship tested in the campus education [29] showed to be of use. Though, performance gains could not be achieved in full, the experience of conducting courses online showed to be quite useful when the whole education was forced to go online because of the COVID pandemic. Academics with the experience of running online courses found it easier to adjust to the new situation than those who did not have this experience. The forced experiment to go online also totally dismissed the myth that an online course requires less teachers' time than the campus ones. The test showed that the opposite was true, despite that some time, like giving lecturers, can be saved through prerecording them.

DSV tried several distance MS programs: Information and Communication Technologies for the Developing world (ICTD), IT Project Management (ITPM), Open eGovernment and Decision Support and Risk Analysis (DSRA). Only the last two programs survived so far. The reasons for DSV not being successful with the first two programs are related to identity, and they are explained below.

Opening the ICTD program was the result of the DSV management being interested in the topic and the Swedish government deciding to provide extra support for this area. The latter resulted in that extra money could be obtained for the program development. The ICTD program was closed several years ago due to the following two factors:

1. Only EU citizens and residents could enroll to this program free of charge; the citizens of the developing countries, who might be more interested in the program, needed to pay. This resulted in the number of enrolled students being too small to justify having the program. The opening of the program did not take into consideration the size of the pool from which the students were drawn. It turned out to be too small.

2. There is a special requirement for having an MS program from Stockholm University (a structural coupling). Namely, the department needs to have the subject of an MS program included in its research areas. The latter ensures that there are enough senior members of staff to supervise MS theses. As the management was unsuccessful in convincing enough senior researchers to enter the area, the program was stopped. The same reason was behind closing the ITPM program, though it attracted quite a lot of students to be enrolled.

\subsection{Summary}

In Section 5, we analyzed a number of examples of past decisions related to identity management understood as maintaining structural couplings. Most of these examples had positive motivation to restore the balance after discovering changes in the structurally coupled elements. Other examples showed that the lack of understanding of some structural couplings created a threat to the department's business activities.

Not all decisions in the examples were motivated by explicit or implicit desire to maintain structural couplings. Some of them were motivated by other reason, e.g., desire to exploit new technology, or personal ambitions of management or academic staff. However, those decision that 
were in line with the existing structural couplings showed to be more successful than those that did not properly consider the importance of one of the structural couplings. This shows the need to test all proposed changes on how they might affect the existing structural couplings before deciding. This is exactly what System 5 of VSM is envisioned to do.

Note that we have not analyzed all past DSV decisions related to identity management. We have just chosen enough examples to cover various structural couplings that DSV has.

\section{Generalization}

In the previous sections, we have presented examples of identifying structural couplings based on FEM diagrams of an organization. We have also analyzed past decisions related to maintenance of these structural couplings, which, according to [5], constitute identity management in an organization. Based on the analysis of the example and our previous works related to structural couplings [12], [13], in this section, we suggest a generic procedure for identifying and managing structural couplings. The rationale behind generalization, based on only one example, is as follows. As was pointed out in [15], researchers on their own cannot fully validate a solution/artefact created in a Design Science project. This can only be done if the practitioners adopt the solution/artefact in their practice. One of the goals for the authors for writing this article was to facilitate such adoption. Just following an example might be a difficult task for a practitioner, especially in a different domain. That is why a generalization, however preliminary, needs to be undertaken in order to disseminate the results and encourage early adopters to try the solution/artefact in their practice.

The generic procedure can also be used as a tool for developing a specific set of rules for identity management in a particular domain, different from the domain of higher education. As the procedure is a generalization of the presented example, the example itself can be considered as a demonstration of the generic procedure. Thus, the status of the procedure becomes more solid than if it were just theoretically developed, but not tested on any example.

The generic procedure consists of the following steps:

1. Build a FEM of an organization in question paying special attention to representing essential assets that need constant refilling, external pools and agents, EXT assets created by external organizations, critical for the business assets and partners that are managing these assets.

2. Following a set of rules summarized in Table 4, detect potential structural couplings that the organization may have. Table 4 encompasses the rules from [13] and the ones added in Section 4. The last rule has been created based on [4], we do not have examples for this rule in [13] or this work, but a case that follows this rule is presented in [30].

3. Investigate whether the indicated potential structural couplings are, in fact, structural couplings. For pool related couplings, determine whether the coupling is to the pool or/and to the external agents connected to the pool. Retrospective analysis of past decisions that affected the identified elements could be of help here.

4. Devise a strategy for maintaining structural couplings. Suggestions for this step are presented in Table 5. They are based on our understanding and interpretation of management literature that is based on a system theoretical perspective, such as [1], [2], [4], and [20]. This table only presents examples of actions aimed at maintaining identity, not the extensive list to choose from.

5. If some structural couplings, which currently exist, present a high risk for the business, consider changing the strategy so that the undesirable couplings become weaker and not important in the long run. Alternatively, have a recoupling strategy to employ when there is a real danger.

6. Check any decision that can affect structural couplings from the point of view of the strategy developed. See to that all structural couplings are maintained; as an action aimed at maintaining a specific structural coupling may negatively affect another structural coupling. FEM diagrams can be used to understand how the implementation of the decision will affect 
structural couplings, and also which assets will need changes; see examples of such considerations in Figures 6-8.

Table 4. Rules for detecting structural couplings

\begin{tabular}{|c|c|c|}
\hline$\#$ & Rule & Name, sources and examples \\
\hline 1 & $\begin{array}{l}\text { If in a FEM of an organization: } \\
\text { 1. there is an essential process, which is not easy to } \\
\text { remove, and } \\
\text { 2. this process has an essential asset with high rate of } \\
\text { depletion, which needs to be constantly filled, and } \\
\text { which is not possible or not easy to remove or } \\
\text { substitute, and } \\
\text { 3. an Acquire process for this asset is connected to an } \\
\text { external pool from which it is getting new elements } \\
\text { to fill the asset, } \\
\text { then the organization is structurally coupled to the } \\
\text { pool or/and to agents connected to this pool. }\end{array}$ & $\begin{array}{l}\text { Inbound pool coupling } \\
\text { [13], Section } 4.1\end{array}$ \\
\hline 2 & $\begin{array}{l}\text { If in a FEM of an organization there is a process that } \\
\text { constantly adds elements to an external pool then the } \\
\text { organization could be structurally coupled to external } \\
\text { agents that draw from this pool, and also to the } \\
\text { external agents that add to the pool. }\end{array}$ & $\begin{array}{l}\text { Outbound pool coupling } \\
{[13], \text { Section } 4.2}\end{array}$ \\
\hline 3 & $\begin{array}{l}\text { If the major activities in an essential for the } \\
\text { organization process happen in a geographical } \\
\text { location and cannot be moved to another location } \\
\text { without substantial disturbance of the organization } \\
\text { functioning, then the organization is structurally } \\
\text { coupled to this geographical location. }\end{array}$ & Section 4.3 \\
\hline 4 & $\begin{array}{l}\text { If in a FEM of an organization, there is an EXT asset } \\
\text { that is created by a third party, and the organization } \\
\text { needs to produce reports related to this asset back to } \\
\text { this party, or/and can expect an inspection to check } \\
\text { the compliance of processes related to this asset, then } \\
\text { the organization could be structurally coupled to the } \\
\text { third party from which the asset originated. }\end{array}$ & $\begin{array}{l}\text { Regulator/Management, } \\
\text { Section } 4.4\end{array}$ \\
\hline 5 & $\begin{array}{l}\text { If in a FEM of an organization: } \\
\text { 1. there is an essential asset, which is impossible or } \\
\text { difficult to substitute by some other (e.g., similar) } \\
\text { asset, and } \\
\text { 2. one or several processes that are used to manage } \\
\text { this asset, i.e., Acquire, Maintain or Retire, have a } \\
\text { Partner asset that is difficult or impossible to } \\
\text { remove or substitute, } \\
\text { then the organization is structurally coupled to the } \\
\text { Partner asset. }\end{array}$ & Essential partner, [13] \\
\hline 6 & $\begin{array}{l}\text { If in a FEM of an organization: } \\
\text { 1. there is a beneficiary asset in a main process, } \\
\text { 2. that also plays a partner role for acquire process for } \\
\text { a stock asset that initiates instances of the main } \\
\text { process (e.g., a stock of manufacturing orders), } \\
\text { 3. and the beneficiary asset consists of one or very } \\
\text { few elements, but as a partner contributes to the } \\
\text { major part of the stock mentioned in condition } 2 \text {, } \\
\text { then the organization is structurally coupled to the } \\
\text { beneficiary asset. }\end{array}$ & $\begin{array}{l}\text { Essential customer, new rule based on [4], an } \\
\text { example is presented in [30]. Added here to } \\
\text { cover all types of structural couplings listed in } \\
\text { [4] }\end{array}$ \\
\hline
\end{tabular}


Table 5. Types of structural couplings and respective identity management

\begin{tabular}{|c|c|c|c|c|}
\hline FEM Diagnostic & $\begin{array}{l}\text { Structural } \\
\text { coupling } \\
\text { variants }\end{array}$ & Explanation & $\begin{array}{l}\text { Potential strategy for } \\
\text { managing the } \\
\text { coupling }\end{array}$ & $\begin{array}{l}\text { Examples of reaction/ } \\
\text { influence type }\end{array}$ \\
\hline \multirow[t]{4}{*}{$\begin{array}{l}\text { 1. Inbound pool } \\
\text { from which entities } \\
\text { to refill an asset are } \\
\text { drawn }\end{array}$} & \multirow[t]{2}{*}{$\begin{array}{l}\text { Pool itself } \\
\text { (market) }\end{array}$} & $\begin{array}{l}\text { Buyers (e.g., potential } \\
\text { customers) in the } \\
\text { marketplace }\end{array}$ & \multirow{2}{*}{$\begin{array}{l}\text { Appropriate explicit or } \\
\text { implicit (e.g., via other } \\
\text { structural coupling) } \\
\text { value proposition, as } \\
\text { well as providing } \\
\text { products and services } \\
\text { accordingly to the } \\
\text { proposition }\end{array}$} & $\begin{array}{l}\text { Adjust product/services } \\
\text { to demand. Influence } \\
\text { buyers to change the } \\
\text { focus of their demands } \\
\text { towards innovative } \\
\text { product and services }\end{array}$ \\
\hline & & $\begin{array}{l}\text { Sellers (Potential } \\
\text { employees or vendors) } \\
\text { in the marketplace }\end{array}$ & & $\begin{array}{l}\text { Adjust contracts, } \\
\text { conditions and } \\
\text { processes, e.g., training, } \\
\text { to the changes in the } \\
\text { market place }\end{array}$ \\
\hline & $\begin{array}{l}\text { Competitors } \\
\text { (drawing } \\
\text { from the } \\
\text { pool) }\end{array}$ & $\begin{array}{l}\text { In case of hard } \\
\text { competition and lack of } \\
\text { established niche } \\
\text { occupied by the } \\
\text { organization }\end{array}$ & $\begin{array}{l}\text { Differentiation, or be } \\
\text { as good as your } \\
\text { competitors }\end{array}$ & $\begin{array}{l}\text { Maintain differentiation } \\
\text { or follow the leader, or } \\
\text { influence others to } \\
\text { follow you }\end{array}$ \\
\hline & $\begin{array}{l}\text { Providers } \\
\text { (adding to the } \\
\text { pool) }\end{array}$ & $\begin{array}{l}\text { If there is a distinct } \\
\text { group of providers that } \\
\text { could be monitored } \\
\text { and/or influenced }\end{array}$ & $\begin{array}{l}\text { Early discovery of } \\
\text { trends in what } \\
\text { providers add or are } \\
\text { willing to add to the } \\
\text { pool }\end{array}$ & $\begin{array}{l}\text { Adjust to the trends } \\
\text { and/or influence } \\
\text { providers to add } \\
\text { elements that are most } \\
\text { suitable for you }\end{array}$ \\
\hline \multirow[t]{2}{*}{$\begin{array}{l}\text { 2. Outbound pool to } \\
\text { which the company } \\
\text { adds elements and } \\
\text { which can be } \\
\text { overflown }\end{array}$} & \multirow[t]{2}{*}{$\begin{array}{l}\text { Organizations } \\
\text { drawing from } \\
\text { the pool }\end{array}$} & $\begin{array}{l}\text { Buyers in the market if } \\
\text { pool is a market }\end{array}$ & $\begin{array}{l}\text { Early discovery of } \\
\text { changes in demands, } \\
\text { finding ways of } \\
\text { influencing the } \\
\text { demands }\end{array}$ & $\begin{array}{l}\text { Adjust to the trends and } \\
\text { needs of the buyers, } \\
\text { influence their demand }\end{array}$ \\
\hline & & $\begin{array}{l}\text { Cleaners if the pool is } \\
\text { waste }\end{array}$ & $\begin{array}{l}\text { Early discovery of } \\
\text { changes in } \\
\text { technology, finding } \\
\text { ways of influencing } \\
\text { the cleaner to clean } \\
\text { your waste }\end{array}$ & $\begin{array}{l}\text { Adjust to the trends and } \\
\text { needs of the cleaners, } \\
\text { make it easier for them } \\
\text { to clean }\end{array}$ \\
\hline $\begin{array}{l}\text { 3. Essential asset } \\
\text { bounded to location }\end{array}$ & $\begin{array}{l}\text { Geographical } \\
\text { location }\end{array}$ & $\begin{array}{l}\text { Essential assets, such as } \\
\text { infrastructure, } \\
\text { workforce, attraction, } \\
\text { etc. are connected to a } \\
\text { certain geographical } \\
\text { region }\end{array}$ & $\begin{array}{l}\text { Looking for trends } \\
\text { that may make the } \\
\text { coupling dangerous } \\
\text { for the organization }\end{array}$ & $\begin{array}{l}\text { Try to decouple in time } \\
\text { if there is a danger }\end{array}$ \\
\hline \multirow[t]{2}{*}{$\begin{array}{l}\text { 4. External producer } \\
\text { of essential/ } \\
\text { mandatory EXT } \\
\text { assets }\end{array}$} & $\begin{array}{l}\text { Upper } \\
\text { management }\end{array}$ & $\begin{array}{l}\text { An upper management } \\
\text { if the organization is } \\
\text { part of a bigger one }\end{array}$ & $\begin{array}{l}\text { Fulfill the obligations, } \\
\text { negotiate resources, be } \\
\text { ready for (surprise) } \\
\text { inspections }\end{array}$ & $\begin{array}{l}\text { Negotiate, adjust itself } \\
\text { to the demands }\end{array}$ \\
\hline & Regulator & $\begin{array}{l}\text { A body that can force } \\
\text { certain regulations, but } \\
\text { do not provide resources }\end{array}$ & $\begin{array}{l}\text { Complying with } \\
\text { existing regulation, } \\
\text { influencing changes in } \\
\text { regulations, be } \\
\text { prepared for (surprise) } \\
\text { inspections }\end{array}$ & $\begin{array}{l}\text { Complying with the } \\
\text { regulations, lobbing for } \\
\text { changes }\end{array}$ \\
\hline $\begin{array}{l}\text { 5. Partner in one or } \\
\text { more processes } \\
\text { responsible for } \\
\text { managing an } \\
\text { essential asset }\end{array}$ & Partner & $\begin{array}{l}\text { An organization that } \\
\text { manages an } \\
\text { essential/critical asset }\end{array}$ & $\begin{array}{l}\text { Influencing the partner } \\
\text { to adapt the asset to } \\
\text { better suit the needs of } \\
\text { the organization }\end{array}$ & $\begin{array}{l}\text { Discuss and argue for } \\
\text { changes }\end{array}$ \\
\hline $\begin{array}{l}\text { 6. Beneficiary of a } \\
\text { main process }+ \text { a } \\
\text { partner managing } \\
\text { initiation of the } \\
\text { process instances }\end{array}$ & Customer & $\begin{array}{l}\text { One or several essential } \\
\text { customers on which the } \\
\text { existence of the main } \\
\text { process depends }\end{array}$ & $\begin{array}{l}\text { Discovering the } \\
\text { changes in customers' } \\
\text { needs, influencing the } \\
\text { changes in customers' } \\
\text { demands }\end{array}$ & $\begin{array}{l}\text { Changing products and } \\
\text { services, educating the } \\
\text { customers }\end{array}$ \\
\hline
\end{tabular}




\section{Conclusion}

The article has three major contributions. Firstly, using an example of analysis of past decisions in an organization, we have demonstrated that the concept of structural coupling can be used as a tool for analyzing and understanding the consequences of decisions. In particular, the following principles can be used when making a decision that intentionally or unintentionally affects/can affect one or more structural couplings:

- When making a decision that affects structural coupling to one of the elements of the environment, there is a need to see how it may affect structural coupling to other elements (see examples in Section 4.4 and 4.5).

- Making changes or allowing them to happen evolutionary while forgetting an important structural coupling may result in an existential threat (see the example in Section 4.2).

- When considering decisions related to structural couplings, there is a need to take into consideration the capabilities that currently exist in the organization. A decision that does not require developing new capabilities, e.g., hiring new people, or convincing the existing staff to change their research directions, has more chances for success than when the development of new capabilities is required, see examples in Section 4.1 and 4.5.

Secondly, we have identified a set of structural couplings for an institution of higher education. Though this has been done for a specific organization, the scheme presented in Figure 5 could be applicable to other institutions of higher education as is, or with modifications, e.g., some institutions can be structurally coupled to their competitors.

Thirdly, we have demonstrated that FEM could serve as a useful tool for identifying structural couplings. We have compiled a set of rules that could be used for this end. Some of these rules are taken from the previous works, others are new. Note, however, that FEM on its own, gives only indications on structural couplings. To be able to decide whether a coupling exists, one needs to conduct business analysis, e.g., whether the asset or process is essential for the organization. Rules, useful for analysis, are presented in Table 4, and extended in Table 5, which also suggests possible strategies for maintaining structural couplings.

So far, the set of rules has not been tested in a situation of new decision-making; it was only used for analysis of the past decisions of one organization. Our future plans include finding business cases where we can test and further develop the rules. More concrete, we are looking for cases for analyzing past decisions as well as cases where a decision that can affect one or more structural couplings needs to be made.

\section{Acknowledgements}

The authors are grateful to Patrick Hoverstadt for his explanations on using structural coupling for defining organizational identity. We would also like to extend our gratitude to our former students, Peggy Poon, Victor Svensson and My Järphed, who completed field studies interviewing our firstyear students and recruiters, as well as our department administration who provided us with the results of a survey conducted among our graduates. The work of the first author was partly supported by the Estonian Research Council (grant PRG1226).

\section{References}

[1] S. Beer, The Heart of Enterprise. Wiley, 1979.

[2] L. Hoebeke, "Identity: the paradoxical nature of organizational closure," Kybernetes, vol. 35, no. 1/2, pp. 6575, 2006. Available: https://doi.org/10.1108/03684920610640236

[3] R. Espejo and A. Reyes, Organizational Systems: Managing Complexity with the Viable System Model. Springer, 2011. Available: https://doi.org/10.1007/978-3-642-19109-1 
[4] P. Hoverstadt and L. Loh, Patterns of Strategy. Taylor \& Francis, 2017. Available: https://doi.org/10.4324/9781315277776

[5] P. Hoverstadt, "Defining Identity by Structural Coupling in VSM Practice," UK Systems Society, Oxford, 2010.

[6] S. Albert and D. Whetten, "Organizational identity," Research in Organizational Behavior, vol. 7, Elsevier, Oxford, pp. 263-295, 1985.

[7] D. A. Whetten, "Albert and Whetten Revisited: Strengthening the Concept of Organizational Identity," Journal of Management Inquiry, vol. 15, no. 3, pp. 219-234, 2006. Available: https://doi.org/10.1177/1056492606291200

[8] H. M. Romesín, "Autopoiesis, Structural Coupling and Cognition: A history of these and other notions in the biology of cognition," Cybernetics \& Human Knowing, vol. 9, no. 3-4, pp. 5-34, 2002.

[9] X. Dumay, H. Draelants, and A. Dahan, "Organizational Identity of Universities: A Review of the Literature from 1972 to 2014," Theory and Method in Higher Education Research, vol. 3, Emerald, pp. 99-118, 2017. Available: https://doi.org/10.1108/S2056-375220170000003006

[10] I. Bider and E. Perjons, "Using Structural Coupling Approach for Defining and Maintaining Identity of an Educational Institution,” Experience Report, STPIS'18, vol. 2107, CEUR, pp. 24-39, 2018.

[11] I. Bider, E. Perjons, M. Elias, and P. Johannesson, "A fractal enterprise model and its application for business development," Software \& Systems Modeling, vol. 16, no. 3, pp.663-689, 2017. Available: https://doi.org/10.1007/s10270-016-0554-9

[12] I. Bider, G. Regev, and E. Perjons, "Using Enterprise Models to Explain and Discuss Autopoiesis and Homeostasis in Socio-Technical Systems," Complex Systems Informatics and Modeling Quarterly, no. 22, pp. 21-38, 2020. Available: https://doi.org/10.7250/csimq.2020-22.02

[13] I. Bider, "Structural Coupling, Strategy and Fractal Enterprise Modeling. Research Challenges in Information Science," RCIS 2020, LNBIP, vol. 385, Springer, pp. 95-111, 2020. Available: https://doi.org/10.1007/978-3030-50316-1_6

[14] A. Hevner, S. T. March, J. Park, and S. Ram, "Design Science in Information Systems Research," MIS Quarterly, vol. 28, no. 1, pp. 75-105, 2004. Available: https://doi.org/10.2307/25148625

[15] I. Bider, P. Johannesson, and E. Perjons, "Design science research as movement between individual and generic situation-problem-solution spaces," Organizational Systems. An Interdisciplinary Discourse, Springer, pp. 3561, 2013. Available: https://doi.org/10.1007/978-3-642-33371-2_3

[16] I. Bider and P. Johannesson, "Just Finished a Cycle of a Design Science Research Project: What's Next?" Complex Systems Informatics and Modeling Quarterly, vol. 22, pp.60-86, 2020. Available: https://doi.org/10.7250/csimq.2020-22.05

[17] P. Johannesson and E. Perjons, An Introduction to Design Science. Springer, 2014. Available: https://doi.org/10.1007/978-3-319-10632-8

[18] N. Luhmann, Introduction to Systems Theory. Polity Press, 2013.

[19] L. Fell and D, Russell “An introduction to 'Maturana's' biology," Seized by agreement, swamped by understanding, Hawkesbury, Sydney, 1994.

[20] P. Hoverstadt, "The Viable System Model," Systems Approaches to Managing Change: A Practical Guide, Springer, pp. 87-133, 2010. Available: https://doi.org/10.1007/978-1-84882-809-4_3

[21] A. Golnam, G. Regev, and A. Wegmann, "On Viable Service Systems: Developing a Modeling Framework for Analysis of Viability in Service Systems," Exploring Services Science, IESS 2011, LNBIP, vol. 82, Springer, pp. 30-41, 2011. Available: https://doi.org/10.1007/978-3-642-21547-6_3

[22] S. G. Scott and V. R. Lane, "A Stakeholder Approach to Organizational Identity," The Academy of Management Review, vol. 25, no. 3, pp. 43-62, 2000. Available: https://doi.org/10.5465/amr.2000.2791602

[23] P. Thornton, "Institutional logics and the historical contingency of power in organizations: Executive succession in the higher education publishing industry, 1958-1990," American Journal of Sociology, vol. 105, pp. 801-843, 1999. Available: https://doi.org/10.1086/210361

[24] M. Henkel, G. Koutsopoulos, I. Bider, and E. Perjons, "Using the Fractal Enterprise Model for Interorganizational Business Processes," ER Forum/Posters/Demos 2019, CEUR, vol. 2469, pp. 56-69, 2019.

[25] UKÄ: Swedish Higher Education Authority (UKÄ). Available: http://english.uka.se/facts-about-highereducation/higher-education-institutions-heis.html

[26] I. Bider and A. Jalali, "Limiting Variety by Standardizing and Controlling Knowledge Intensive Processes," Proceedings of 2016 IEEE 20th International Enterprise Distributed Object Computing Workshops, EDOCW 2016, pp.33-41, 2016. Available: https://doi.org/10.1109/EDOCW.2016.7584366 
[27] J. Biggs and C. Tang, Teaching for Quality Learning at University. 4th ed. Open University Press, 2011.

[28] I. Bider and D. Rogers, "YASQLT - Yet Another SQL Tutor. A Pragmatic Approach," Advances in Conceptual Modeling (ER workshops 2016), LNCS, vol. 9975, Springer, pp.197-206, 2016. Available: https://doi.org/10.1007/978-3-319-47717-6_17

[29] I. Bider, M. Henkel, S. Kowalski, and E. Perjons, "Simulating apprenticeship using multimedia in Higher Education: a case from the information systems field," Interactive Technology and Smart Education, vol. 12, no. 2, pp. 137-154, 2015. Available: https://doi.org/10.1108/ITSE-04-2015-0004

[30] I. Bider and A. Chalak, "Evaluating Usefulness of a Fractal Enterprise Model Experience Report," Enterprise, Business-Process and Information Systems Modeling. BPMDS 2019, EMMSAD 2019, LNBIP, vol. 352, Springer, pp. 359-373, 2019. Available: https://doi.org/10.1007/978-3-030-20618-5_24 